\title{
Effects of biological disturbance on diversity and structure of meiobenthic nematode communities
}

\author{
Melanie C. Austen*, Stephen Widdicombe, Nicoletta Villano-Pitacco \\ Centre for Coastal and Marine Sciences, Plymouth Marine Laboratory, Prospect Place, West Hoe, \\ Plymouth PL1 3DH, United Kingdom
}

\begin{abstract}
Benthic mesocosm experiments have shown that subtidal macrofauna species with con trasting feeding behaviour and mobility can alter the structure of natural subtidal meiobenthic nematode assemblages. Test macrofauna species were the bivalves Nuculoma tenuis (subsurface-deposit feeder) and Abra alba (surface-deposit/suspension feeder) at 3 different densities and the heart urchin Brissopsis lyrifera (subsurface burrowing deposit feeder) at a single density. $\alpha$ and $\beta$ nematode diversity were affected by disturbance of different intensities in the bivalve treatments in a way that is consistent with the intermediate disturbance hypothesis regardless of type of disturbance. These measures of community structure did not differentiate between contrasting types of disturbance. Multivariate community analysis indicated that the species response in the assemblage was more sensitive to the type of disturbance than the intensity of disturbance. Differential responses of the nematode species did not reflect their depth distribution in natural field sediment and the likely depth at which the test macrofauna species were active. Nor was the response simply a predator-prey interaction with certain species targeted by the predator; the interactions appear to be more complex. Our experimental results suggest that patches of sediment which are dominated by high abundances or biomass of one or a few species, a situation which is encountered in the field, are important in maintaining regional diversity. These patches will create a heterogeneous mosaic of communities with different diversities and different species compositions.
\end{abstract}

KEY WORDS: Meiofauna - Nematode - Diversity - Community structure $\cdot$ Predation - Disturbance Abra alba Nuculoma tenuis - Brissopsis lyrifera

\section{INTRODUCTION}

The distribution of macrobenthic communities can be spatially and temporally patchy in apparently homogeneous, subtidal sediment environments. Variations in recruitment often result in patches of sediment which are dominated by particularly high abundances or biomass of one or a few species. High abundance or biomass of an individual species will result in greater intensity of biological disturbance to other components of the benthic community. This disturbance may take the form of predation (e.g. Ambrose 1991) or physical disruption of sediment structure. Predation may be completely selective or partially selective by size-spe-

·E-mail:m.austen@pml.ac.uk cific ingestion or non-selective ingestion of sediment. Sediment disturbance results from activities of an organism, such as movement through the sediment matrix or the creation of tubes, burrows and casts in or on the sediment. Physical disturbance can cause sediment resuspension and instability, and it can also affect sediment chemistry (e.g. Widdicombe \& Austen in press). Numerous studies indicate that predation and sediment disturbance caused by individual species can affect associated macrobenthic and meiobenthic community structure and diversity (e.g. Reise 1977, 1979, White et al. 1980, Castel 1984, Warwick et al. 1986, 1990a, Reidenauer 1989, Hall et al. 1991, Ólafsson \& Elmgren 1991, Posey et al. 1991, Ólafsson et al. 1993, Aarnio et al. 1998, Austen \& Widdicombe 1998). These individual species can have disproportionate effects on community structure in relation to their 
abundance or biomass. If the disturbance effect of a single individual is great enough, then it may not even necessarily be an abundance or biomass dominant of the community. Ambrose (1991) suggests that different groups of infaunal predators will probably play different roles in structuring soft-bottom communities based on their trophic position and mechanisms of interacting with their prey. The nature of biological disturbance from different species will vary according to morphological, behavioural and functional differences between species. It therefore seems unlikely that the effects on associated community structure of different types of disturbance by dominant macrobenthic species will be equivalent.

The effects of disturbance on communities have been modelled primarily with respect to community diversity. In this respect attention has focused on the relationship between the intensity of disturbance and $\alpha$ diversity of a community. Intensity of disturbance has been succinctly defined by Petraitis et al. (1989) as the weighted rate of disturbance, i.e. disturbance size multiplied by frequency. There is an assumption in the modelling literature that disturbance is a quantifiable unit of damage to a system, i.e. a quantity of disturbance will have a known effect. As far as we are aware, diversity theories relating to disturbance make the assumption that disturbance is qualitatively similar and that only the intensity of disturbance will affect community structure. In the empirical world it is presently impossible to equate intensities of biological disturbance, for example in soft sediment is the disturbance created by 1 burrowing heart urchin equivalent to that of the same biomass of mobile deposit feeding bivalves? Studies of the effects of biological disturbance on soft sediment communities have generally only examined the effects of single species. Where the effects of more than 1 species have been described the experimental design does not allow statistical comparison of the effects of different species (Reise 1979).

The intermediate disturbance hypothesis is one currently accepted model of diversity that predicts that highest diversity will be at intermediate intensities of disturbance (Connel 1978). There are now many examples of this pattern occurring in nature (see, e.g. Huston 1994). We have carried out biological disturbance experiments on sublittoral soft sediment communities in mesocosms which compared the effects on associated benthic communities of 3 potentially differently disturbing macroinvertebrate species at different densities. Abra alba is a surface-deposit/suspension feeding bivalve, it feeds using its siphons which move around on and above the surface sediment. During feeding the animal itself is largely stationary. Nuculoma tenuis is a subsurface-deposit feeding bivalve, and it is smaller and more compact than Abra but has a denser shell. Nuculoma feeds using labial palps and is much more mobile whilst feeding than Abra. Brissopsis lyrifera, the heart urchin, is a burrowing, subsurface non-selective deposit feeder with an adult size of $3 \mathrm{~cm}$ across the test. We report here the results of experiments with these 3 species on the dominant nematode component of the meiofauna community. We have examined the effects of biological disturbance on measures of $\alpha$ and $\beta$ diversity and on species composition and community structure. Our hypotheses are (1) diversity and community structure change with differing intensities of biological disturbance, for diversity measures these changes are consistent with the intermediate disturbance hypothesis and (2) the effects of disturbance are the same regardless of the type of biological disturbance.

\section{METHODS}

Experimental design. The experiment was carried out in the soft bottom mesocosm of the NIVA Marine Research station at Solbergstrand, south of Drøbak, on the eastern shore of Oslofjord, Norway. The mesocosm has been described in detail by Berge et al. (1986). The $4.9 \times 7 \mathrm{~m}$ indoor, epoxy resin coated concrete basin used for this experiment had a water depth of $100 \mathrm{~cm}$. Water was continuously pumped in via a pipe situated outside the marine station at a depth of $60 \mathrm{~m}$ in the Oslofjord. Low level lighting was set for a $10 \mathrm{~h}$ daily period.

On 3 and 4 April 1995, fresh sandy mud sediment was collected with a Day grab at $30 \mathrm{~m}$ depth from Bjorhodenbukta $\left(59^{\circ} 42.8^{\prime} \mathrm{N}, 10^{\circ} 32.2^{\prime} \mathrm{W}\right)$, a small bay in the inner part of Oslofjord. The sediment was thoroughly mixed to ensure homogeneity, and any visibly obvious large macrofauna $(>1.5 \mathrm{~cm})$ were removed. The sediment was used to fill 4 boxes, $1 \times 1 \mathrm{~m}$ and $30 \mathrm{~cm}$ deep, to a depth of $22 \mathrm{~cm}$. These boxes were placed in the mesocosm basin, where they were allowed to settle for $9 \mathrm{~d}$.

After this period each box was partitioned into 14 small areas of $817 \mathrm{~cm}^{2}$ and 2 large areas of $176.7 \mathrm{~cm}^{2}$ using mesh cages. The small cages (Fig. 1a) were constructed of $10 \mathrm{~cm}$ lengths of $102 \mathrm{~mm}$ diameter plastic pipe to which a circular band of mesh net was glued to give an overall height of $23 \mathrm{~cm}$. A mesh size of $0.5 \mathrm{~mm}$ was chosen to contain added macrofauna but allow free movement of meiofauna in and out of the cages. Large cages were similarly constructed (Fig. 1a) from $7.5 \mathrm{~cm}$ lengths of $150 \mathrm{~mm}$ diameter pipe, and overall height was again $23 \mathrm{~cm}$. Using a $4 \times 4\left(1 \mathrm{~m}^{2}\right)$ quadrat, cages were positioned in each box (Fig. 1b) so that they were approximately equidistant from each other and the edges of the box. The position of the large parti- 
(a)

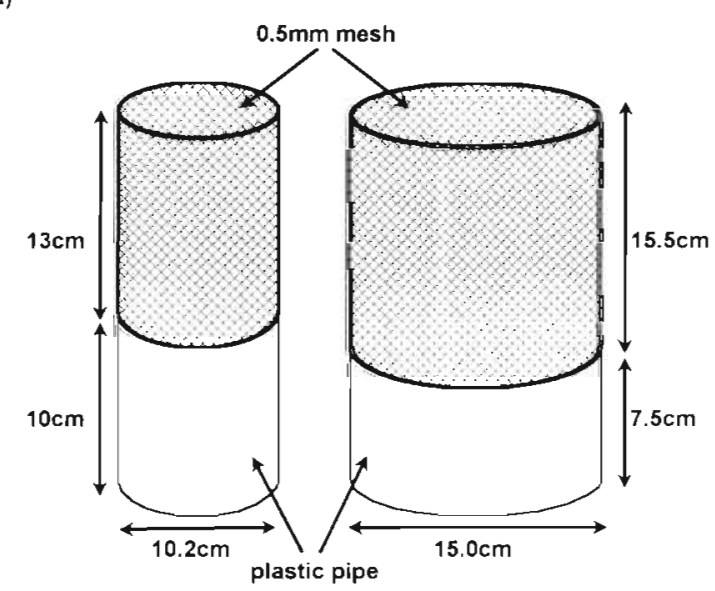

(b)

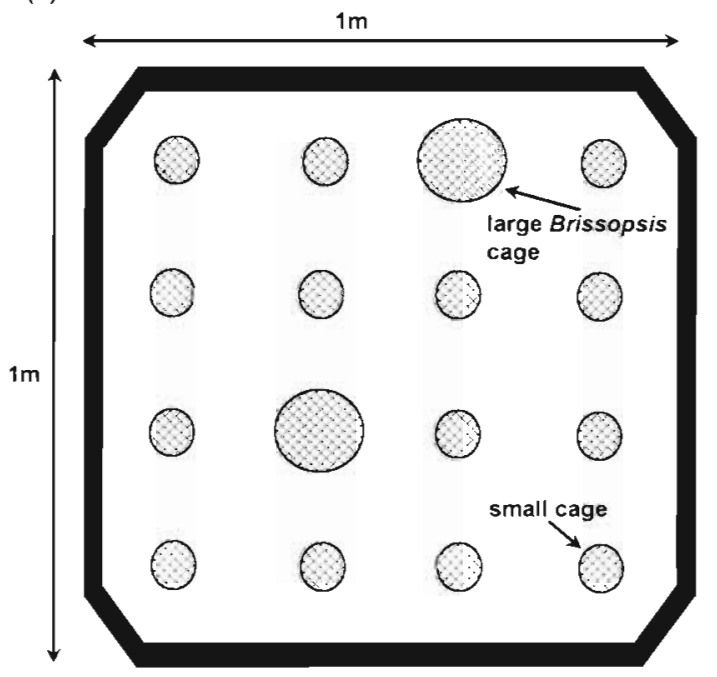

Fig. 1. (a) Design and dimensions of small and large cages (b) Layout of cages in each of 4 replicate $1 \mathrm{~m}^{2}$ boxes in the mesocosm. Positions of large cages and treatments were randomly allocated

tioned areas within each box was randomly allocated within the grid of partitioned areas. Thus, each partitioned area had the same amount of surrounding sediment available for meiofauna immigration/emigration. Cages were pushed down into the sediment until the plastic base sat on the floor of the box with the top $10 \mathrm{~mm}$ of mesh cage protruding from the surface of the sediment, thus preventing escape of enclosed macrofauna from either under or over the walls of the cages.

Nuculoma tenuis (size range 0.67 to $1.18 \mathrm{~cm}$, mean length $0.88 \mathrm{~cm}$ ) and Brissopsis lyrifera (size range 2.8 to $3.2 \mathrm{~cm}$, mean length $3 \mathrm{~cm}$ ) were collected from 3 to 10 April using a Day grab at the same sediment collection site in Bjørhodenbukta. Abra alba (size range 1.22 to $2.04 \mathrm{~cm}$, mean length $1.55 \mathrm{~cm}$ ) were supplied by Kristineberg Marine Research Station, Sweden on 4
April. They were collected using a $0.5 \mathrm{~m}$ Agassiz bottom dredge from $11 \mathrm{~m}$ depth in Ellös Fjord on the Swedish west coast from mud clay sediment with shell debris. The macrofauna were held in the mesocosm basin prior to their addition to the cages on 12 April 1995.

Controls and 7 treatments were replicated once in each of the 4 boxes of sediment. Controls consisted of small partitioned areas to which no macrofauna were added. Brissopsis treatments were the large partitioned areas to which $1 B$. lyrifera was added (equivalent to 57 ind. $\mathrm{m}^{-2}$ ); the 2 bivalve species were added at 3 different densities: Nuculoma low, Nuculoma medium and Nuculoma high, corresponding to 5, 12 and 25 bivalves per small partitioned area respectively (612, 1469 and 3059 ind. $\mathrm{m}^{-2}$ ), and Abra low, Abra medium and Abra high, corresponding to 5, 15 and 27 bivalves per small partitioned area respectively $(612$, 1836 and 3304 ind. $\mathrm{m}^{-2}$ ).

Sampling and sample analysis. Sampling took place nearly 20 wk later on 29 August 1995. The water level in the mesocosm basin was dropped to below the depth of the boxes. Three meiofauna cores were taken from each partitioned area using a $50 \mathrm{ml}$ syringe (22 $\mathrm{mm}$ internal diameter) to a depth of $5 \mathrm{~cm}$. The cores were amalgamated to form a sample representative of each cage and then fixed in $10 \%$ formalin. The remaining sediment in each partitioned area was sieved on a $0.5 \mathrm{~mm}$ mesh to collect all surviving macrofauna.

Meiofauna was extracted from the sediment using 3 flotations in Ludox TM at a specific gravity of 1.15 decanted into a $63 \mu \mathrm{m}$ sieve (Austen \& Warwick 1989). Meiofauna subsamples $(20 \%)$ were taken using a $45 \mathrm{ml}$ ladle after the samples had been adjusted to $900 \mathrm{ml}$ with tap water and vigorously mixed to homogenise them (Austen \& Warwick 1989). Subsamples were placed in $10 \%$ glycerol, evaporated to anhydrous glycerol, and then mounted on slides for microscopic identification. Nematodes were the dominant meiobenthic taxa (>90\% of the total abundance) and these were identified to genus, or species where practicable, and enumerated.

Data analysis. Two-way ANOVA was used to test for differences in univariate measures computed in the PRIMER (Plymouth Routines in Multivariate Ecological Research) software package: total nematode abundance, number of nematode species, Shannon Wiener diversity ( $\log _{\mathrm{e}}$ ), Margalef's species richness and Pielou's evenness (Clarke \& Warwick 1994). Bartlett's test was used to determine whether variances were non-homogeneous and the data required transformation. Where Bartlett's test indicated nonhomogeneity of variances, data was $\log _{10}$ transformed and Bartlett's test was repeated to confirm that variance was homogeneous following transformation. The Dunnett test was used to test for significant differ- 
Table 1. Mean (and SD) abundance and biomass of Nuculoma tenuis and Abra alba added to experimental treatments and recovered at the end of the experiment. Biomass was determined as blotted wet weight after decalcification in $10 \%$ formic acıd

\begin{tabular}{|lcccccc|}
\hline Treatment & No. added & $\begin{array}{c}\text { Nuculoma tenuis } \\
\text { No. recovered }\end{array}$ & Bionass (g) & No. added & $\begin{array}{c}\text { Abra alba } \\
\text { No. recovered }\end{array}$ & $\begin{array}{c}\text { Biomass (g) } \\
\text { Low }\end{array}$ \\
Medium & $5(0)$ & $4.5(1.2)$ & $0.198(0.097)$ & $5(0)$ & $4.6(1.2)$ & $0.229(0.101)$ \\
High & $11.5(0.8)$ & $10.25(1.0)$ & $0.468(0.095)$ & $14.6(0.7)$ & $13.9(1.2)$ & $0.882(0.168)$ \\
& $24.5(0.5)$ & $22.625(2.8)$ & $1.085(0.198)$ & $26.9(0.4)$ & $26.1(0.8)$ & $1.537(0.270)$ \\
\hline
\end{tabular}

ences between the treatments and controls, and Tukey HSD, adjusted for multiple comparisons, was used to test for differences between treatments. ANOVA, Dunnett and Tukey HSD tests were carried out using SYSTAT vers, 5.03. A significance level of $p<0.05$ was used in all tests.

Rarefaction (Hurlbert 1971, Simberloff 1972) and species area curves were constructed using the BioDiversity Professional Beta software package (produced by the Natural History Museum and the Scottish Association for Marine Science). Rarefaction curves provide a measure of species diversity which permits comparison of $\alpha$ diversity between communities where abundances vary. The model predicts the expected number of species for a given abundance of individuals, and the calculation was based on a gap of 50 individuals. The slope of species area curves can be used to indicate differences in species turnover, a measure of $\beta$ diversity ( $\mathrm{He} \&$ Legendre 1996). In both rarefaction and species area plots a steeper curve is representative of higher diversity.

Multivariate data analysis followed methods described by Clarke \& Warwick (1994) and Clarke (1993) using the PRIMER software package. The data were subjected to non-metric multi-dimensional scaling ordination (MDS) with the Bray-Curtis similarity measure. Untransformed data analysis is more sensitive to changes in abundance of the dominant specjes, but increasingly severe square root and double square root transformations are more sensitive to changes in lower abundance and rarer species. Therefore analysis was carried out using a range of these transformations to determine the effects of the treatments on different components of the community. Two-way crossed ANOSIM was carried out to determine if there were any box or treatment effects. If there are no global box effects, it is then acceptable to use the more powerful 1 -way pairwise ANOSIM test for significant differences $(p<0.05)$ between meiobenthic assemblages in different treatments and the controls (M. Carr, Plymouth Marine Laboratory, pers. comm.). SIMPER was used to determine the contribution of individual species towards dissimilarity between treatments and controls.

\section{RESULTS}

Recovery of macrofauna from the cages at the end of the experiment (Table 1) was good, with a mean survival rate of 91,95 and $100 \%$ for Nuculoma tenuis, Abra alba and Brissopsis lyrifera respectively. There were no effects of box on nematode community structure (2-way crossed ANOSIM) and further multivariate data analysis was carried out using 1-way ANOSIM. Univariate data satisfied conditions for ANOVA and data transformation was not necessary. There were no significant box effects on any of these indices (2-way ANOVA, Table 2). Abiotic conditions remained constant throughout the experiment: salinity was maintained at $34.5 \pm 0.5 \mathrm{psu}$ and temperature at $7 \pm 1^{\circ} \mathrm{C}$.

\section{Univariate measures}

There were significant treatment effects on nematode community structure for the univariate measures of total number of species, Shannon Wiener diversity and species richness (ANOVA, Table 2). Very few significant differences between controls and treatments and between treatments were observed in pairwise comparisons using Dunnett's test and Tukey's HSD test (Table 3). Four of the 5 univariate indices, number of species, abundance, Shannon Wiener diversity and species richness, responded with similar trends to the

Table 2. F-ratio values from 2-way ANOVA for univariate indices of nematode community structure with $p$-values in parentheses. Underlined values indicate significant effects,

$$
p<0.05
$$

\begin{tabular}{|c|c|c|c|}
\hline & Treatment & Box & $\begin{array}{c}\text { Treatment-Box } \\
\text { interactions }\end{array}$ \\
\hline Degrees of freedom & 7 & 3 & 21 \\
\hline Number of species & $7.28(0.00)$ & $2.64(0.07)$ & $1.31(0.24)$ \\
\hline Abundance & $2.06(0.08)$ & $0.48(0.70)$ & $0.88(0.61)$ \\
\hline $\begin{array}{l}\text { Shannon-Wiener } \\
\text { diversity }\end{array}$ & $4.33(0.00)$ & $0.55(0.65)$ & $1.24(0.28)$ \\
\hline Species richness & $7.39(0.00)$ & $2.50(0.08)$ & $1.27(0.26)$ \\
\hline Evenness & $2.31(0.06)$ & $1.55(0.22)$ & $2.04(0.03)$ \\
\hline
\end{tabular}


bivalve density treatments, although the response differed between the 2 bivalve species treatments (Fig. 2). There was no clear response in the evenness index, which varied little between the low, medium and high density treatments of each bivalve treatment.

In the Nuculoma treatments, maximum mean values of the indices number of species, abundance, Shannon Wiener diversity and species richness were in the medium density treatments (Fig. 2). Low density treatments had higher mean values of these indices than the high density treatments, and all 3 Nuculoma treatments had greater mean index values than the control. These differences were significant for number of species, species richness and Shannon Wiener diversity (Table 3) only in pairwise comparisons of control and medium density treatment, and control and low density treatment (except Shannon Wiener diversity). The total number of species was significantly higher in the medium density than the high density Nuculoma treatments (Table 3).
In the Abra treatments there was a decrease in mean value of the indices abundance, number of species, species richness and Shannon Wiener diversity from low density to high density treatments. Number of species and species richness were significantly lower in the high density treatment in comparison with the low density treatment (Table 3). Number of species, abundance and species richness were significantly higher in the low density treatments than in the controls (Table 3). High density Abra treatments had lower mean numbers of species, Shannon Wiener diversity and species richness values than the controls, but none of these differences were statistically significant.

Brissopsis treatments had slightly higher nematode abundances and numbers of species than the controls but these differences were not significant (Table 3).

Some of the Abra and Nuculoma treatments had significantly different univariate indices of number of species, species richness and Shannon Wiener diver-

Table 3. p-values from pairwise comparisons of univariate indices of nematode community structure between treatments and controls using Dunnett's test adjusted for multiple comparisons and between treatments using Tukey's HSD test adjusted for multiple comparisons. Underlined values indicate significant differences, $p<0.05$

\begin{tabular}{|c|c|c|c|c|c|c|c|}
\hline & Control & $\begin{array}{c}\text { Nuculoma } \\
\text { low }\end{array}$ & $\begin{array}{l}\text { Nuculoma } \\
\text { medium }\end{array}$ & $\begin{array}{c}\text { Nuculoma } \\
\text { high }\end{array}$ & $\begin{array}{l}\text { Abra } \\
\text { low }\end{array}$ & $\begin{array}{c}\text { Abra } \\
\text { medium }\end{array}$ & $\begin{array}{l}\text { Abra } \\
\text { high }\end{array}$ \\
\hline \multicolumn{8}{|l|}{ Abundance } \\
\hline Nuculoma low & 0.541 & & & & & & \\
\hline Nuculoma medium & 0.077 & 0.948 & & & & & \\
\hline Nuculoma high & 1.00 & 0.930 & 0.370 & & & & \\
\hline Abra low & 0.038 & 0.852 & 1.000 & 0.231 & & & \\
\hline Abra medium & 0.062 & 0.925 & 1.000 & 0.323 & 1.000 & & \\
\hline Abra high & 0.806 & 1.00 & 0.812 & 0.991 & 0.650 & 0.765 & \\
\hline Brissopsis & 0.373 & 1.00 & 0.987 & 0.836 & 0.940 & 0.977 & 0.996 \\
\hline \multicolumn{8}{|c|}{ Total number of species } \\
\hline Nuculoma low & 0.040 & & & & & & \\
\hline Nuculoma medium & 0.000 & 0.608 & & & & & \\
\hline Nuculoma high & 0.772 & 0.644 & 0.023 & & & & \\
\hline Abra low & 0.004 & 0.977 & 0.977 & 0.175 & & & \\
\hline Abra medium & 0.413 & 0.911 & 0.083 & 0.999 & 0.425 & & \\
\hline Abra high & 0.984 & 0.019 & $\underline{0.000}$ & 0.570 & $0.00 \underline{2}$ & 0.269 & \\
\hline Brissopsis & 0.345 & $\overline{0.94 .4}$ & $\overline{0.108}$ & 0.995 & 0.497 & 1.000 & 0.218 \\
\hline \multicolumn{8}{|l|}{ Species richness } \\
\hline Nuculoma low & 0.040 & & & & & & \\
\hline Nuculoma medium & 0.000 & 0.706 & & & & & \\
\hline Nuculoma high & 0.609 & 0.762 & 0.056 & & & & \\
\hline Abra low & 0.015 & 1.000 & 0.899 & 0.521 & & & \\
\hline Abra medium & 0.849 & 0.533 & 0.022 & 1.000 & 0.305 & & \\
\hline Abra high & 0.733 & 0.003 & 0.000 & 0.134 & 0.001 & 0.272 & \\
\hline Brissopsis & 0.609 & 0.762 & 0.056 & 1.000 & 0.521 & 1.000 & 0.134 \\
\hline \multicolumn{8}{|c|}{ Shannon Wiener diversity } \\
\hline Nuculoma low & 0.413 & & & & & & \\
\hline Nuculoma medium & 0.046 & 0.919 & & & & & \\
\hline Nuculoma high & 0.743 & 0.999 & 0.677 & & & & \\
\hline Abra low & 0.970 & 0.957 & 0.370 & 0.999 & & & \\
\hline Abra medium & 1.000 & 0.447 & 0.048 & 0.755 & 0.954 & & \\
\hline Abra high & 0.211 & 0.006 & 0.000 & 0.026 & 0.087 & 0.520 & \\
\hline Brissopsis & 1.000 & 0.659 & 0.105 & 0.909 & 0.994 & 1.000 & 0.323 \\
\hline
\end{tabular}



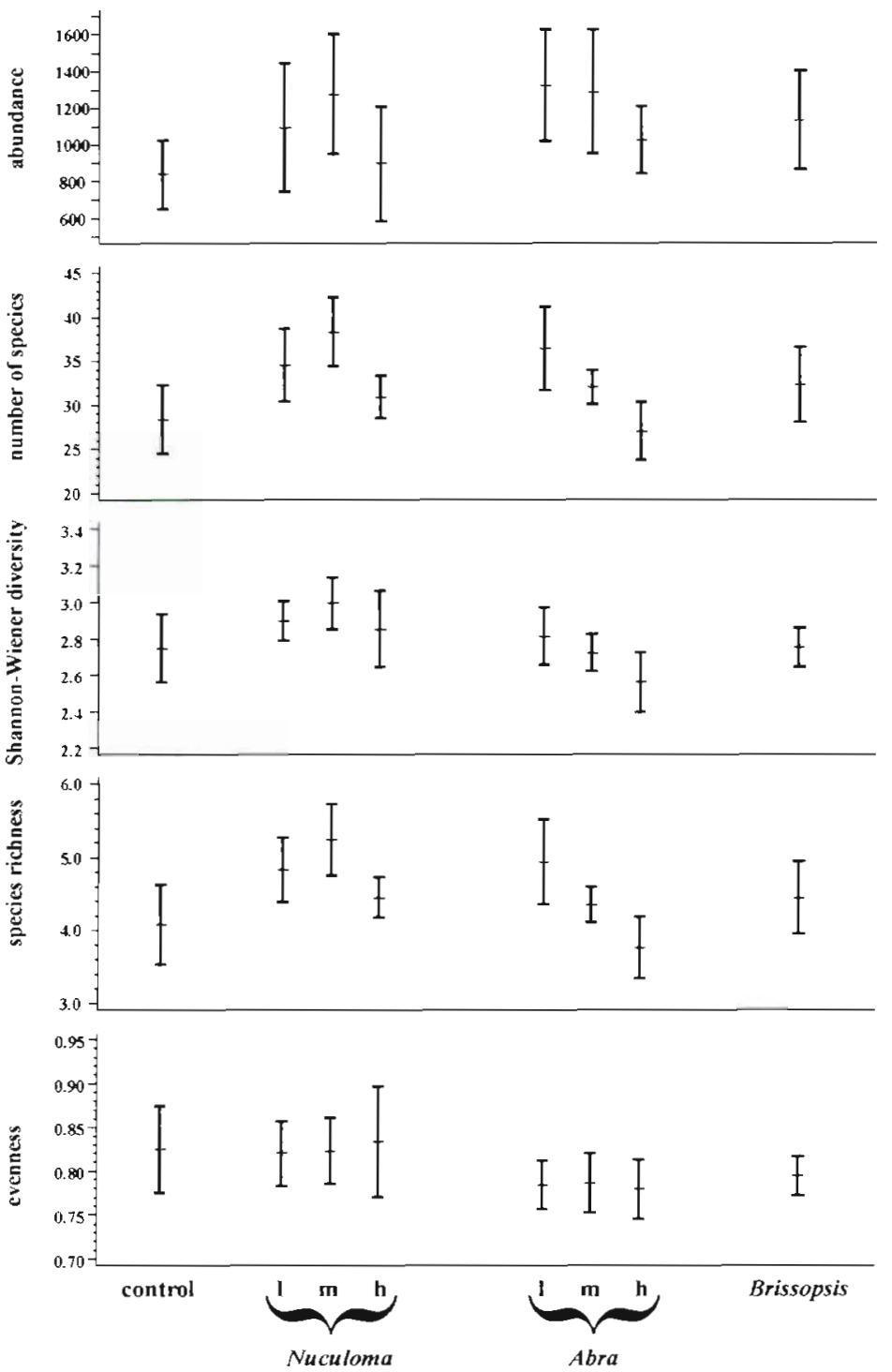

Fig. 2. Mean univariate measures of nematode assemblage structure with standard error bars. $1, \mathrm{~m}$ and h correspond to low, medium and high density treatments respectively

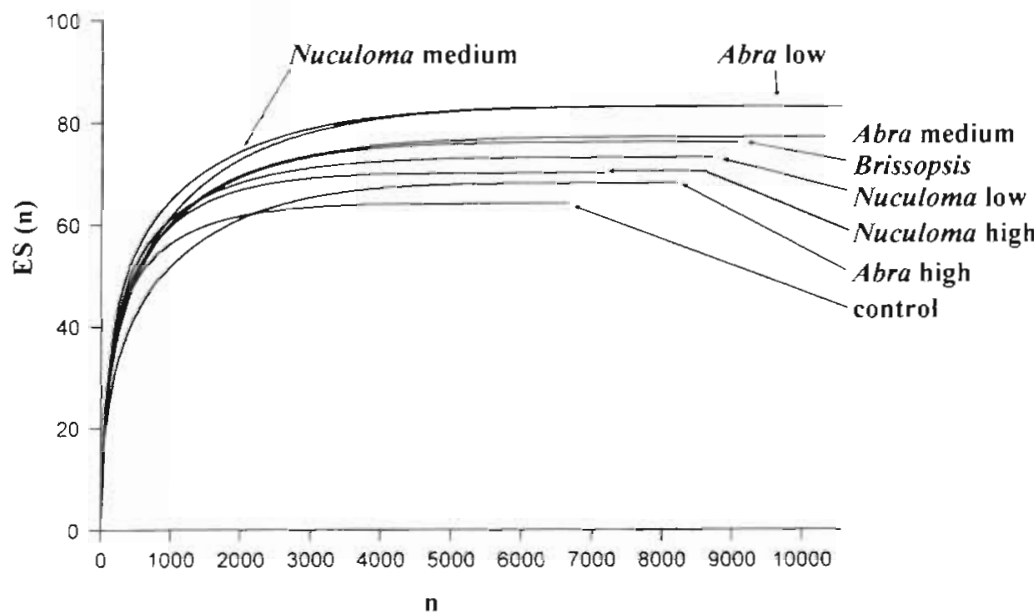

sity, but the Brissopsis univariate indices were not significantly different from any of the Nuculoma or Abra treatments (Table 3, Fig. 2). The patterns of diversity were repeated in the rarefaction plot (Fig. 3), indicating that they were not simply a reflection of the different abundance measures in the treatments.

\section{Species area curves $-\beta$ diversity}

The species area curves (Fig. 4) indicate that when compared with the control almost all treatments (except Abra high density) increased the heterogeneity and hence $\beta$ diversity of the nematode assemblage. There are no tests for significance of differences between these curves. $\beta$ diversity followed the same trends as the $\alpha$ diversity measuresnumber of species, species richness and Shannon Wiener diversity. Maximum 3 diversity occurred in the Nuculoma medium and Abra low density treatments. Nuculoma low density treatments had higher diversity than Nuculoma high density treatments. Abra medium density treatments had higher diversity than Abra high density treatments.

\section{Multivariate analysis}

Results from 1-way ANOSIM tests are given in Table 4. The number of significant differences in pairwise comparisons between the different faunal treatments decreased with increasingly severe data transformation. Thus dominant and more abundant nematode species were more affected by the treatments than rarer lower abundance species. Because the results are quite similar, MDS ordinations are shown for analysis carried out on untransformed data only (Figs. 5 \& 6). From Fig. 5 and Table 4 it can be seen that there were significant differences between the controls and most of the treatments and between many of the different faunal treatments. The Abra treatments are most dissimi-

Fig. 3. Rarefaction curves computed for a gap of 50 individuals. ES( $\mathrm{n})$ : expected number of species; n: number of nematode individuals 


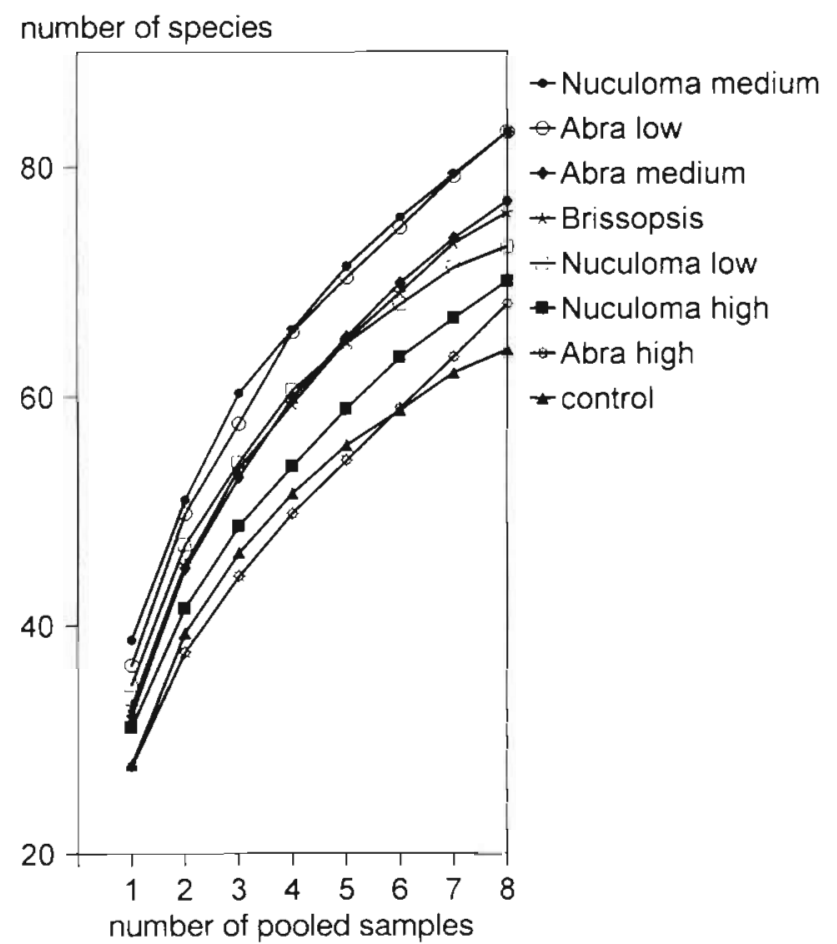

Fig. 4. Nematode species-area curves based on 50 random sorts lar from the controls and the Nuculoma treatments most similar. The Brissopsis treatments are intermediate between the bivalve treatments.

The different density treatments have been included in Fig. 5, but with so much data it is difficult to see the relationship between all the different treatments. However, even when the MDS ordination is carried out on the bivalve treatments and control data alone (Fig, 6), it is not possible visually to clearly distinguish any bivalve density related effects. The ANOSIM results (Table 4) confirm that there are no significant differences in nematode community structure between the different Nuculoma density treatments or between medium and high density Abra treatments. Abra low and high density treatments were significantly different from each other when the data were transformed (Table 4), the Abra low density treatment was significantly different from the medium density treatment only when the data were single root transformed. The variation in results according to the severity of data transformation indicate that dominant species in the nematode community were less affected by the different density Abra treatments than were commonly occurring but less abundant species. The low abundance species also differed between the low and high density Abra treatments.

Table 4. R-values from pairwise comparisons of treatments using 1-way ANOSIM. Underlined values indicate significant differences, $p<0.05$

\begin{tabular}{|c|c|c|c|c|c|c|c|}
\hline & Control & $\begin{array}{c}\text { Nuculoma } \\
\text { low }\end{array}$ & $\begin{array}{l}\text { Nuculoma } \\
\text { medium }\end{array}$ & $\begin{array}{l}\text { Nuculoma } \\
\text { high }\end{array}$ & $\begin{array}{l}\text { Abra } \\
\text { low }\end{array}$ & $\begin{array}{c}\text { Abra } \\
\text { medium }\end{array}$ & $\begin{array}{l}\text { Abra } \\
\text { high }\end{array}$ \\
\hline \multicolumn{8}{|l|}{ Data not transformed } \\
\hline Nuculoma low & 0.076 & & & & & & \\
\hline Nuculoma medium & 0.164 & -0.039 & & & & & \\
\hline Nuculoma high & $\underline{0.169}$ & 0.039 & 0.063 & & & & \\
\hline Abra low & 0.421 & 0.092 & $\underline{0.161}$ & 0.269 & & & \\
\hline Abra medium & $\underline{0.434}$ & 0.292 & $\underline{0.196}$ & $\underline{0.250}$ & 0.061 & & \\
\hline Abra high & 0.525 & 0.442 & 0.422 & 0.381 & 0.098 & -0.029 & \\
\hline Brissopsis & $\underline{0.286}$ & 0.172 & 0.123 & $\underline{0.193}$ & 0.057 & 0.110 & 0.248 \\
\hline \multicolumn{8}{|c|}{ Data square root transformed } \\
\hline Nuculoma low & 0.115 & & & & & & \\
\hline Nuculoma medium & $\underline{0.184}$ & -0.101 & & & & & \\
\hline Nuculoma high & 0.120 & 0.039 & 0.062 & & & & \\
\hline Abra low & $\underline{0.348}$ & 0.042 & 0.042 & $\underline{0.226}$ & & & \\
\hline Abra medium & 0.371 & $\underline{0.296}$ & 0.177 & $\underline{0.170}$ & 0.117 & & \\
\hline Abra high & $\underline{0.468}$ & $\underline{0.506}$ & $\underline{0.480}$ & 0.306 & 0.252 & 0.023 & \\
\hline Brissopsis & 0.228 & 0.102 & 0.056 & 0.079 & -0.022 & 0.069 & $\underline{0.233}$ \\
\hline \multicolumn{8}{|c|}{ Data double square root transformed } \\
\hline Nuculoma low & 0.087 & & & & & & \\
\hline Nuculoma medium & $\underline{0.158}$ & -0.133 & & & & & \\
\hline Nuculoma high & 0.045 & 0.013 & 0.058 & & & & \\
\hline Abra low & $\underline{0.211}$ & -0.016 & -0.064 & 0.085 & & & \\
\hline Abra medium & $\underline{0.217}$ & $\underline{0.221}$ & $\underline{0.117}$ & 0.071 & 0.083 & & \\
\hline Abra high & 0.322 & $\underline{0.415}$ & 0.414 & $\underline{0.191}$ & $\underline{0.270}$ & 0.072 & \\
\hline Brissopsis & 0.153 & $\overline{0.034}$ & 0.022 & -0.021 & $-\overline{0.075}$ & 0.024 & 0.165 \\
\hline
\end{tabular}




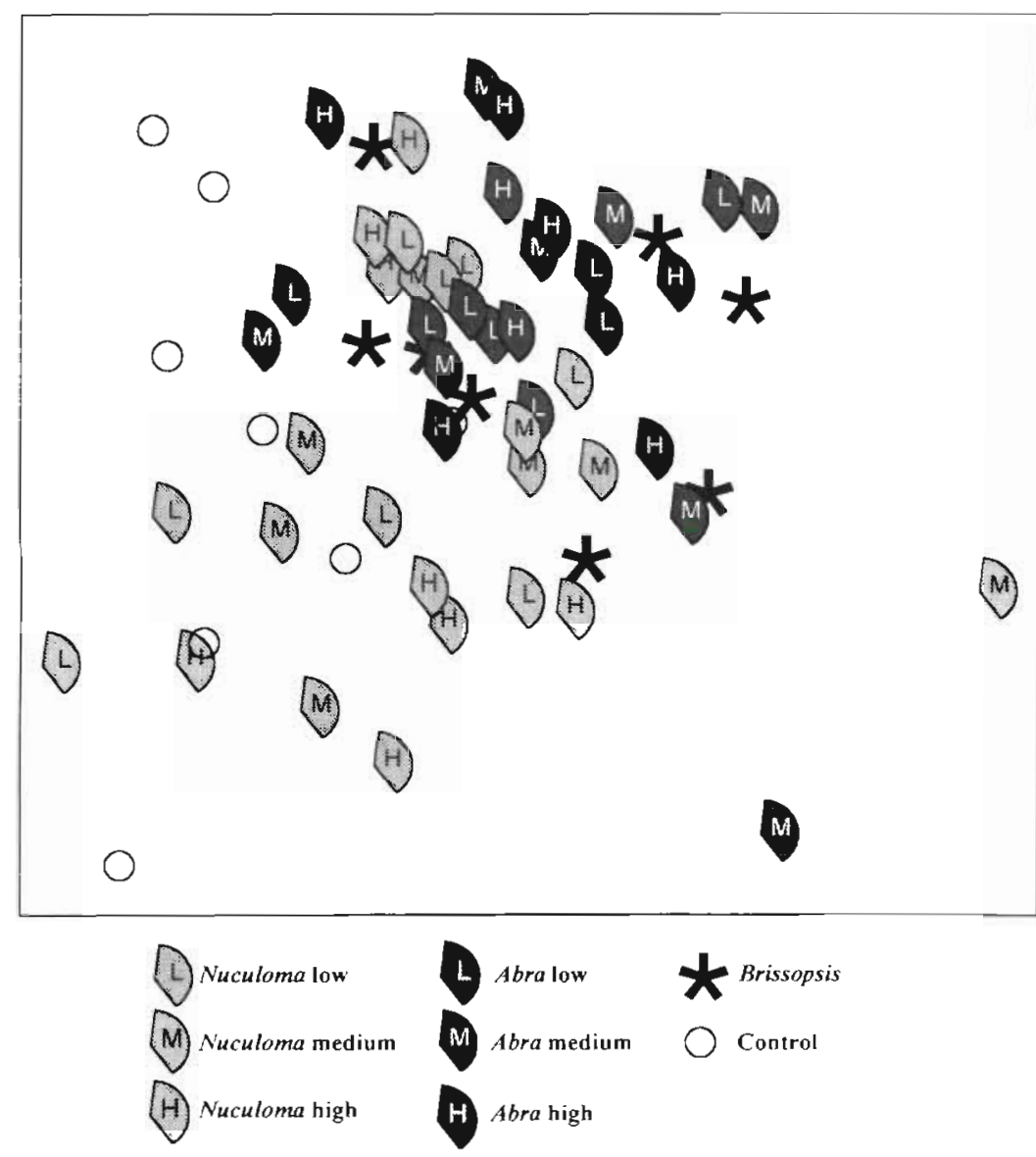

Fig. 5. Non-metric multi-dimensional scaling (MDS) ordinations of nematode abundance data using untransformed data, with superimposed symbols indicating both faunal. type and density treatment, stress $=0.22$ were higher as the analysis is more highly influenced by the most abundant species. Even in these analyses at least 6 species contributed to the first $50 \%$ of the dissimilarity between treatments and controls, with a highest individual species contribution of $16.6 \%$ (S parasitifera in the comparison of the control and the Nuculoma high density treatment). From all the pairwise comparisons of the treatments made using untransformed data, the highest individual species contribution was $19.7 \%$ (S. parasitifera in the comparison of Nuculoma and Abra high density treatments).

All samples had the same species composition amongst the dominant nematodes. Dissimilarities between treatments were due to combinations of generally small increases or decreases in abundances of different species which were consistent amongst replicates. From Fig. 7, it is evident that, even with 8 replicate treatments, individual species abundance in whole-community experiments is quite variable, making it impossible to statistically detect significant differences between populations in different treatments. Using SIMPER and Fig. 7 it is possible to determine changes in direction of abundance of the dominant species in different treatments. Mean abundance of

\section{Nematode species responses}

Differences between treatments and controls were mostly due to changes in the more abundant nematode species (SIMPER analysis). Abundances and $95 \%$ confidence intervals of these species are given in Fig. 7. It is apparent that differences between treatments were a community response from most of the more abundant species and were not unduly influenced by only 1 or 2 highly dominant species. In the square root transformed data SIMPER analysis, the maximum contribution made by any single species to the overall Bray-Curtis dissimilarity between samples was $6.4 \%$ (Spininia parasitifera in the comparison of the Abra high and Nuculoma high density treatments). Usually only 1 to 4 species contributed more than $4 \%$ each to the overall Bray-Curtis dissimilarity between samples, with the remaining percentage contributed by many species as contributions of 1 to $3 \%$. In the untransformed data SIMPER analysis, the contributions to overall Bray Curtis dissimilarity between samples by single species
Terschellingia longicaudata decreased in all treatments relative to the controls (excepting Nuculoma low density), but several dominant species, particularly Odontophora longisetosa, Laimella longicaudata, Dorylaimopsis punctata and Sabatieria sp. juveniles, had increased mean abundances in treatments relative to the controls. Spirinia parasitifera, the most abundant nematode, decreased in Nuculoma medium density treatments relative to the control but increased in all other treatments. Several species had higher mean abundances in Abra treatments than Nuculoma treatments, e.g. S. parasitifera, O. Iongisetosa, Rhabdocomasp. and $D$. punctata. $T$. longicaudata mean abundance decreased with increasing macrofauna density and was lower in Abra and Brissopsis treatments than in Nuculoma treatments. Metalinhomoeus sp. mean abundance increased in the Nuculoma low and medium density treatments but decreased in the high density and in the Abra and Brissopsis treatments. The major difference between Brissopsis treatments and the controls and other treatments was elevated abundances of $O$. longise- 

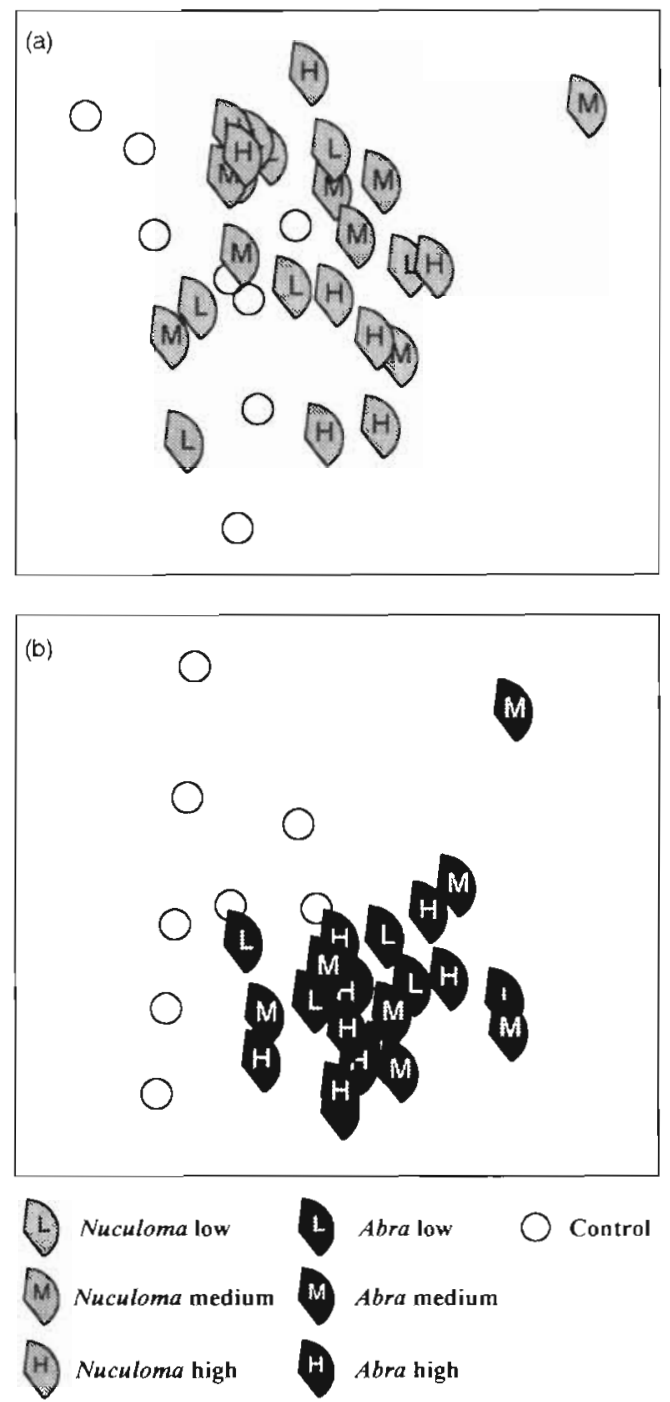

Fig. 6. Non-metric multi-dimensional scaling (MDS) ordinations of nematode abundance data using untransformed data, with superimposed symbols indicating faunal type and density treatment. (a) Nuculoma treatments and controls, stress =

0.19 , (b) Abra treatments and controls, stress $=0.18$

tosa. $O$. longisetosa also increased in the bivalve treatments, but the greatest abundance increase was in the Brissopsis treatments, followed by the Abra treatments and then the Nuculoma treatments. Generally, nematode species responses to the Brissopsis treatments were not consistently similar to either the Nuculoma or Abra treatments, e.g. S. parasitifera, D. punctata and Cobbia sp. abundances in the Brissopsis treatments were similar to those in the Nuculoma treatments and the controls, Rhabdocoma sp. abundance was intermediate between that in the Nuculoma and Abra treatments but $T$. longicaudata, Metalinhomoeus sp. and Sabatieria sp. had similar mean abundances in the Abra and Brissopsis treatments

\section{DISCUSSION}

The meiofaunal response to disturbance from $\mathrm{NuCu}$ loma tenuis suggests that it fits the predictions of the intermediate disturbance hypothesis (Connel 1978), with peak $\alpha$ and $\beta$ diversity at intermediate levels of disturbance (Figs. 2 to 4 ). Elevated diversity values at low and sometimes even medium densities of Abra alba in comparison to the controls suggests that again the meiofaunal response fits the intermediate disturbance model except that the $A$. alba disturbance was more intense. This is not surprising since $A$. alba are larger and have a greater biomass, and in the medium and high abundance species treatments there were slightly greater abundances of $A$. alba than $N$. tenuis. Comparing the diversity values the intensity of disturbance created at intermediate experimental densities of $N$. tenuis was approximately equivalent to that created by $A$. alba at low experimental densities.

Thayer (1983) provided a review of available data for sediment reworking volumes of different species: Nucula proxima, a species which is morphologically and behaviourally similar to Nuculoma tenuis, from $18 \mathrm{~m}$ depth in Buzzards Bay, Massachusetts, USA, reworks $<0.3 \mathrm{~cm}^{3} \mathrm{~d}^{-1}$ via resuspension, with sediment being reworked from $2 \mathrm{~cm}$ depth to the surface. Thayer (1983) gives a figure of $<0.8 \mathrm{~cm}^{3} \mathrm{~d}^{-1}$ for Abra nitida, which is morphologically and behaviourally similar to Abra alba, from 460 to $680 \mathrm{~m}$ depth in Korsfjorden, Norway. Thayer points out that the reworking by $A$. nitida is predominantly via manipulation in feeding, and sediment is reworked at the surface to a depth of $0.5 \mathrm{~cm}$. Unfortunately, similar figures for Brissopsis lyrifera are not available. If the above values are applied to the experimental treatments, then the Nuculoma medium density and the Abra low density treatments had similar sediment reworking rates of 3.6 and $4.0 \mathrm{~cm}^{3} \mathrm{~d}^{-1}$ respectively. This level of disturbance corresponded approximately to an intermediate rate at which the highest diversity is observed in the nematode community. Univariate measures of community structure, such as diversity, responded to changes in disturbance in a way that suggested there is a uniform response to intensity of disturbance regardless of the nature of the disturbance.

In contrast, multivariate analysis indicated that the species-specific response was much more dependant on the quality of disturbance, and this had a greater effect on nematode community structure than quantity of disturbance. Nematode communities showed more significant differences between treatments with different macrofaunal disturbers than they did between treatments with the same disturber but where intensity of disturbance differed. In microcosm experiments of 2 mo duration Olafsson \& Elmgren (1991) also ob- 

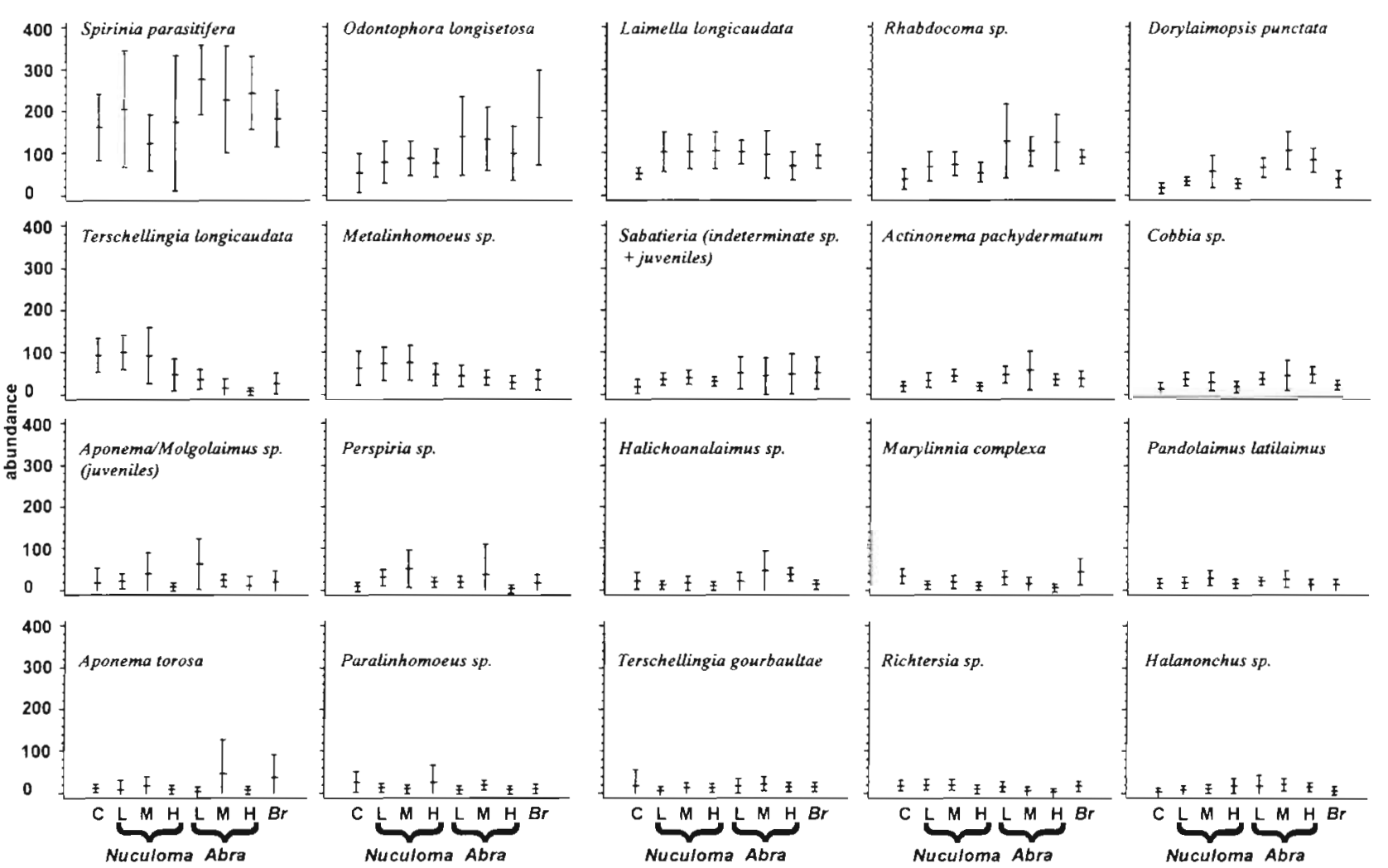

Fig. 7. Mean abundances with $95 \%$ confidence intervals of the 20 most abundant species and genera in all treatments. C: control; Br: Brissopsis treatments; L, M, H: low, medium and high density Nuculoma or Abra treatments

served some indications that Baltic nematode diversity was higher in the presence of medium densities of the surface-deposit feeding amphipod Monoporeia affinis (medium disturbance), but multivariate nematode assemblage structure did not vary between different amphipod density treatments. Our results suggest that a community that is responding to disturbance may vary in species composition depending on the nature of the disturbance. If species composition is representative of community function, then the community may also vary functionally. In contrast, species diversity appears to vary consistently with the intensity of disturbance regardless of the nature of that disturbance. The different response to disturbance of these 2 different properties of community structure clearly has important ecological and conservation implications.

In a similar experimental design, Austen \& Widdicombe (1998) observed significant differences in multivariate structure of nematode communities in treatments with 2 different densities of Brissopsis lyrifera. Variability was much higher in the univariate indices and there was no indication that the response fitted the intermediate disturbance hypothesis. This is in contrast to the results we present here and further highlights qualitative differences between bioturbating fauna such as bivalves and echinoderms and their effects on associated communities. In Austen and Widdicombe's experiment it was noted that abundance of Odontophora $\mathrm{sp}$. increased in the presence of $B$. lyrifera, and the reasons for this are largely unknown. We also observed an increase in Odontophora longisetosa in the Brissopsis treatments in this experiment, indicating that this is a repeatable result. Odontophora is probably a characteristic genus in areas dominated by high densities of $B$. lyrifera, although this has yet to be proven in field surveys.

The literature records for sediment depth distribution of nematodes (e.g. Platt 1977, Jensen 1983, Warwick \& Gee 1984, Ólafsson \& Elmgren 1991, Soetart et al. 1994) suggest that the dominant species in our samples were probably subsurface dwellers found deeper than $1 \mathrm{~cm}$. Despite the different feeding modes of the macrofauna disturbers, there does not seem to be any specific response from the nematodes that can be related to the likely depth at which the macrofaunal disturbers would have greatest impact. This may be a reflection on the experimental design: the communities were vertically homogeneous at the start of the experiment and the initial $9 \mathrm{~d}$ settlement period may have been insufficient for the nematodes to re-estab- 
lish a natural vertical community structure prior to the addition of the macrofauna. Nematodes can also be classified into different nematode feeding groups according to the structures in their buccal cavity (Wieser 1953). Group $2 \mathrm{~b}$ nematodes, the omnivore/ predators, were significantly affected by treatment $\left(\log _{10}\right.$ transformed data ANOVA, $F=2.74, p=0.02$ ). The dominant species in this group was Halichoanalaimus sp., which increased sufficiently in the Abra medium and high density treatments to make the group $2 b$ feeding group abundances significantly higher than those in the Nuculoma high density treatment (Tukey HSD, $\mathrm{p}<0.05$ ). Otherwise there is no indication that there was a feeding group response to particular types of macrofaunal disturbance.

The effects of the disturbance probably did not arise through direct predation or mortality caused by sediment disturbance, as there was almost no significant effect on nematode abundances. In all cases mean nematode abundances in the treatments were greater than in the control (but only significantly so for the Abra low density treatment). Nematode density appears to be elevated at intermediate levels of disturbance. At the highest experimental densities of $A$. alba and Nuculoma tenuis, there was a reduction in nematode abundance compared to the other treatments, suggesting that these species did cause some mortality at these densities.

Abra alba predominantly removes particles in the size range 15 to $60 \mu \mathrm{m}$ through its siphon and into the mantle cavity. It then selectively ingests smaller particles (predominantly 15 to $45 \mu \mathrm{m}$ ), and only a much smaller proportion of larger particles (up to $180 \mu \mathrm{m}$ ) are found in the stomach (Hughes 1975). Its predatory effects would be generally limited to very small species and juvenile nematodes, which we did not sample, with larger nematodes being taken only rarely. Cheng \& Lopez (1991) experimentally determined that Nucula proxima, a species very similar to Nuculoma tenuis, selectively feeds on sedimentary organic matter and associated bacteria, with the latter more efficiently utilised than the former. However there is no literature available, as far as we are aware, to indicate the size range of particles ingested by nuculanid bivalves. As previously discussed by Austen \& Widdicombe (1998), Brissopsis lyrifera has no particle size selection when feeding and appears to be a non-selective deposit feeder. A very wide range of material has been observed in the gut of $B$. lyrifera, including polychaetes. It seems likely that coincidental consumption and digestion of meiofauna occurs when sediment is non-selectively ingested.

The 3 macrofaunal test species therefore probably do not prey significantly on nematodes. They perhaps could have more direct effects on the predators or feeding competitors of nematodes, such as predatory meiofauna and juvenile and adult macrofauna, again either through predation (Brissopsis lyrifera only) or mortality caused by sediment disturbance. Macrofauna may be more sensitive than meiofauna to sediment disturbance (Austen et al. 1989, Warwick et al. 1990b, Widdicombe \& Austen unpubl.) due to decreased sediment stability, increased sediment resuspension and physical damage to external structures. The macrofauna communities did change in response to the 3 macrofaunal test species, i.e. abundance and numbers of species decreased in comparison to the control in all but the Nuculoma low density treatments, although very few of the decreases were significant (Widdicombe \& Austen pers, obs.). Reduction in meiofaunal predators and competitors could lead to an increase in nematode abundance and change in community structure.

Alternatively, the disturbance activity of the macrofauna test species may have stimulated microbial growth and increased sediment oxygenation, providing an increase in food and spatial resources which in turn stimulated the nematodes. Through bioturbation and predation, deposit feeders modify the sediment microorganism communities; they can stimulate microorganism growth and sometimes they can increase bacterial production via cultivation on aggregates (Amouroux et al. 1989 and references therein). Reise (1983) observed increased densities of meiofaunal polychaetes and turbellarians in field caging experiments with the tellinid bivalve Macoma balthica. Reise proposed that $M$. balthica actively promotes microbial growth around itself by enriching the sediment with nutrients and thus culturing or 'gardening' its own food source. Increased meiofaunal densities may have been due to increased food availability resulting from this gardening. The feeding behaviour of $M$. balthica is very similar to that of Abra alba, hence the disturbance effects of $A$. alba may be similarly related to changes in microbial composition of the sediment.

Warwick et al. (1986) observed fine scale differences in distribution of nematode assemblages across faecal mounds and feeding areas of the polychaete Streblosoma bairdi within the mesocosms at Solbergstrand. They proposed that this was due to the influence of the polychaete on the nature of the primary food resource available to the meiofauna. Spirinia parasitifera was most abundant at the centre of the faecal mounds, and they suggested that it is attracted to the food source provided by bacteria growing on freshly produced faecal pellets. There is the possibility in our experiment that faeces and pseudofaeces produced by the bivalves may have attracted certain nematode species as the associated bacteria would be a potential food source. 
Reise (1983) also suggested that, since the exhalent siphon of Macoma balthica is below the sediment surface, expulsion from it can create enriched oxygen areas which are attractive for certain species of meiofauna. The exhalent siphon of Abra alba is also below the sediment surface, and the same situation may apply to this species. Wikander (1980) has observed that siphonal channels of Abra species play an important role in bringing oxygen down to the deeper strata of the sediment. Nuculanid bivalves can increase sediment resuspension and change the structure of the surface sediment (Rhoads \& Young 1970, Davis 1993). Nucula proxima reworks silt and clay sized particles into sand sized faecal pellets, and its frequent lateral movements displace mud, consequently producing sand sized and larger clasts of semi-consolidated sediment (Rhoads \& Young 1970).

Widdicombe \& Austen (1998) demonstrated that Brissopsis lynifera alters sediment chemistry, probably through oxygenation. $B$. lyrifera is a shallow burrower and it is in the surface $3 \mathrm{~cm}$ of the sediment that its activity is likely to result in lowered sediment stability. This disturbance combined with respiratory activity of B. lyrifera changes the sediment chemistry, probably increasing oxygenation of the sediment to deeper levels. Alteration of the physical and chemical properties of the sediment by the macrofauna could have influenced nematode community structure.

The 3 macrofauna species used in our experiment to act as potential sediment disturbers/predators all have similar effects on the sediment to a degree, but the mechanics and the areas of effect are different. The gradient of response observed in the nematode assemblages is reflected in these mechanisms. Nuculoma tenuis has quite large physical sediment movement effects due to its random lateral movements in the sediment whilst it searches for food, but it has little or no direct predatory effect on either the meiofauna or their predators. At high $N$. tenuis densities nematode abundance may have been reduced due to competition with the bivalves for available food resources. Abra alba is probably less motile, and therefore less physicaily disruptive in the sediment than $N$. tenuis or Brissopsis lyrifera, but still increases sediment oxygenation through its feeding activities A. alba probably affected the nematodes through a small amount of direct predation, particularly in the high density treatment, where other food could have been limited. Again, in this treatment there may also have been direct competition between the nematodes and $A$. alba for food. B. lyrifera also disrupts the physical structure of the sediment substantially and also could have a greater predatory effect than the other 2 species due to coincidental consumption of nematodes whilst feeding.
In the context of the intermediate disturbance hypothesis (Connel 1978), increased food resource and oxygen availability at intermediate levels of disturbance may have reduced competition for these resources, thus increasing diversity. However our experiments are not able to distinguish whether competitive interactions play a role in creating the diversity patterns observed in response to disturbance

It should be noted that our observations are confounded by those of Olafsson et al. (1993) from a 5 mo microcosm disturbance experiment with the bivalve Macoma balthica. In their experiment $M$. balthica, at densities similar to those used in our experiments, had no effect on Baltic nematode community structure. The sediment used in their experiment was initially sieved through a $0.5 \mathrm{~mm}$ sieve to remove macrofauna. Possibly the macrofauna they removed are a key link in the effects of larger macrofauna species on the smaller meiofauna, but we cannot at present suggest a mechanism for this functional role. In our experiment the associated macrofaunal communities were also affected by the 3 macrofaunal test species (Widdicombe \& Austen pers. obs.). Ólafsson \& Ndaro (1997), in another microcosm experiment, found nematode communities were also resilient to reworking of the sediment surface by mangrove crabs over a $10 \mathrm{~d}$ period. They give 2 possible explanations for this: firstly, the animals either live below the surface $2 \mathrm{~mm}$ which are disturbed by the crab or move below this depth when the crabs disturb the sediment; secondly, the experimental time period may have been too short to show any effect.

In our experiments the 3 macrofaunal species clearly did affect the associated nematode community structure, but it might be argued that the experimental densities used were artificially high. Certainly within Oslofjord there are no published field data indicating that that Nuculoma tenuis or Abra alba attain even our highest experimental densities. Valderhaug \& Gray (1984) recorded a mean abundance for $N$. tenuis during July 1981 to June 1983 of $483 \mathrm{~m}^{-2}(\mathrm{SD}=106)$ at our sediment collecting site in Bjerhodenbukta, whilst $A$. alba is in fact rather rare there. We observed localised patches of high densities of Brissopsis lyrifera (5 to 15 individuals in $0.1 \mathrm{~m}^{2}$ Day grabs, Austen \& Widdicombe unpubl.). Published information concerning temporal and spatial variability of the fauna in the Oslofjord is at present hardly exhaustive, and there are indications that in other parts of the north Atlantic the experimental densities we used were not unrealistic. Dauvin et al. (1993) reviewed population data for $A$. alba in the English Channel and Southern North Sea. Populations were extremely variable temporally, for example at Gravelins the population varied in the range 0 to 8907 ind. $\mathrm{m}^{-2}$ over a $14 \mathrm{yr}$ period. The high- 
est $A$. alba abundance these authors give is 17900 ind $\mathrm{m}^{-2}$ in Rade de Lorient, where the population ranged from 200 to 17900 ind. $\mathrm{m}^{-2}$ over the period 1982 to 1984. Off the river Elbe, Caspers (1980) found densities of $A$. alba as high as 17500 ind. $\mathrm{m}^{-2}$ in the centre of a sewage sludge dumping ground as well as high numbers of Nucula turgida (4360 ind. $\mathrm{m}^{-2}$ ) outside of the dumping ground. Closer to Oslofjord, Muus (1973) also found $A$. alba densities to be very variable temporally, both within and between 2 stations in the Oresund. Densities $>3000 \mathrm{~m}^{-2}$ were recorded at one of the stations, although many of these were newly settled spat. $N$. tenuis has a wide range of variability and was found at densities ranging from 417 to $2231 \mathrm{~m}^{-2}$ over a 2 yr period in Loch Etive, Scotland (Harvey \& Gage 1995).

Our experiment suggests that the presence of patches of sediment dominated by high abundances or biomass of one or a few species of macrofauna, a situation which can be encountered in the field, is important in maintaining regional diversity. These patches will create a heterogeneous mosaic of communities with different diversities and different species compositions, i.e. enhanced $\beta$ diversity. Different types of disturbance appear to affect the species composition differentially and hence probably also the functional properties of a community, even though the pattern of change in species diversity is constant regardless of the nature of the disturbance

Acknowledgements. This work was enabled by a grant from the EC Access to Large Scale Facilities Programme and was funded by the UK Ministry of Agriculture Fisheries and Food project number AE1113. We are indebted to Torgeir Bakke, John Arthur Berge, Liv Berge and Joanna Maloney of NIVA Oslo for helping to facilitate this work, to Hảkon Oen, Einar Johannesen and Oddbjarn Pettersen for their technical support at the Solbergstrand Marine Station and to the crew of RV 'Trygve Braarud' Critical and constructive comments from Richard Warwick, Mike Kendall and Michaela Schratzberger have improved the manuscript, and Bob Clarke and Martin Carr advised on the statistical design and analysis of the experiment. This paper is a contribution to Plymouth Marine Laboratory's Marine Biodiversity research project.

\section{LITERATURE CITED}

Aarnio K, Bonsdorff E, Norkko A (1998) Role of Halicryptus spinulosus (Priapulida) in structuring meiofauna and settling macrofauna. Mar Ecol Prog Ser 163:145-153

Ambrose WG Jr (1991) Are infaunal predators important in structuring marine soft-bottom communities? Am Zool 31 $849-860$

Amouroux JM, Grémare A, Amouroux J (1989) Modelling of consumption and assimilation in Abra alba (Mollusca, Bivalvia). Mar Ecol Prog Ser 51:87-97

Austen MC, Warwick RM (1989) Comparison of univariate and multivariate aspects of estuarine meiobenthic community structure. Estuar Coast Shelf Sci 29:23-42

Austen MC, Warwick RM, Rosado MC (1989) Meiobenthic and macrobenthic community structure along a putative pollution gradient in Southern Portugal. Mar Pollut Bull 20:398-405

Austen MC, Widdicombe S (1998) Experimental evidence of effects of the heart urchin Brissopsis lyrifera on associated subtidal meiobenthic nematode communities. J Exp Mar Biol Ecol 222:219-238

Berge JA, Schanning M, Bakke T, Sandøy K, Skeie GM, Ambrose WG Jr (1986) A soft bottom sublittoral mesocosm by the Oslofjord: description, performance, and examples of applications. Ophelia 26:31-54

Caspers $H$ (1980) Long term changes in benthic fauna resulting from sewage sludge dumping into the North Sea. Prog Wat Technol 12:461-479

Castel J (1984) Influence de l'activité bioperturbatrice de la Palourde (Ruditapes philippinarum) sur les communautés meiobenthiques. CR Acad Sci Paris Ser III 299:761-764

Cheng IJ, Lopez GR (1991) Contributions of bacteria and sedimentary organic matter to the diet of Nucula proxima, a deposit-feeding protobranchiate bivalve. Ophelia 34: $157-170$

Clarke KR (1993) Non-parametric multivariate analyses of changes in community structure. Aust J Ecol 18:117-143

Clarke KR, Warwick RM (1994) Changes in marine communities: an approach to statistical analysis and interpretation. Natural Environment Research Council, Swindon

Connel JH (1978) Diversity in tropical rain forests and coral reefs. Science 199:1302-1310

Dauvin JC, Dewarumez JM, Elkaim B, Bernardo B, Fromentin JM, Ibanez F (1993) Cinétique de Abra alba (mollusque bivalve) de 1977 à 1991 en Manche-Mer du Nord, relation avec les facteurs climatique. Oceanol Acta 16:413-4.22

Davis WR (1993) The role of bioturbation in sediment resuspension and its interaction with physical shearing. J Exp Mar Biol Ecol 171:187-200

Hall SJ, Basford DJ, Robertson MR, Raffaelli DG, Tuck I (1991) Patterns of recolonisation and the importance of pit-digging by the edible crab Cancer pagurus in a shallow subtidal sand habitat. Mar Ecol Prog Ser 72:93-102

Harvey R, Gage JD (1995) Reproduction and recruitment of Nuculoma tenuis (Bivalvia: Nuculoida) from Loch Etive, Scotland. J Mollusc Stud 61:409-419

He $F$, Legendre $P$ (1996) On species-area relations. Am Nat 148:719-737

Hughes TG (1975) The sorting of food particles by Abra sp. (Bivalvia: Tellinacea). J Exp Mar Biol Ecol 20:137-156

Hurlbert SH (1971). The non-concept of species diversity: a critique and alternative parameters. Ecology 52:577-586

Huston MA (1994) Biological diversity. Cambridge University Press, Cambridge

Jensen $\mathrm{P}$ (1983) Meiofaunal abundance and vertical zonation in a sublittoral soft bottom, with a test of the Haps corer. Mar Biol 74:319-326

Muus K (1973) Settling, growth and mortality of young bivalves in the Øresund. Ophelia 12:79-116

Olafsson E, Elmgren R (1991) Effects of biological disturbance by benthic amphipods Monoporeia affinis on meiobenthic community structure: a laboratory approach. Mar Ecol Prog Ser 74:99-107

Olafsson E, Elmgren R, Papakosta O (1993) Effects of the deposit-feeding benthic bivalve Macoma balthica on meiobenthos. Oecologia 93:457-462

Olafsson E, Ndaro SGM (1997) Impact of the mangrove crabs Uca annulipes and Dotilla fenestrata on meiobenthos. Mar Ecol Prog Ser 158:225-231

Petraitis PS, Latham RE, Niesenbaum RE (1989) The maintenance of species diversity by disturbance. Q Rev Biol 64 : $393-418$ 
Platt HM (1977) Vertical and horizontal distribution of freeliving marine nematodes from Strangford Lough, Northern Ireland. Cah Biol Mar 18:261-273

Posey MH, Dumbauld BR. Armstrong DA (1991) Effects of a burrowing mud shrimp, Upogebia pugettensis (Dana), on abundances of macro-infauna. J Exp Mar Biol Ecol 148: $283-294$

Reidenauer JA (1989) Sand-dollar Mellita quinquiesperforata (Leske) burrow trails: sites of harpacticoid disturbance and nematode attraction. J Exp Mar Biol Ecol 130:223-235

Reise K (1977) Predator exclusion experiments in an intertidal mud flat. Helgol Wiss Meeresunters 30:263-271

Reise K (1979) Moderate predation on meiofauna by the macrobenthos of the Wadden Sea. Helgol Wiss Meeresunters 32:453-465

Reise K (1983) Biotic enrichment of intertidal sediments by experimental aggregates of the deposit-feeding bivalve Macoma balthica. Mar Ecol Prog Ser 12:229-236

Rhoads DC, Young DK (1970) The influence of deposit-feeding organisms on sediment stability and community trophic structure. J Mar Res 28:150-178

Simberloff D (1972) Properties of the rarefaction diversity measurement. Am Nat 106:414-418

Soetart $K$, Vincx M, Wittoeck J, Tulkens M, Van Gansbeke D (1994) Spatial patterns of Westerschelde meiobenthos. Estuar Coast Shelf Sci 39:367-388

Thayer CW (1983) Sediment-mediated biological disturbance and the evolution of marine benthos. In: Tevesz MJS, McCall PL (eds) Biotic interactions in recent and fossil benthic communities. Plenum Press, New York, p 479-625

Valderhaug VA, Gray JS (1984) Stable macrofauna community structure despite fluctuating food supply in subtidal

Editorial responsibility: Otto Kinne (Editor),

Oldendort/Luhe, Germany soft sediments of Oslofjord, Norway. Mar Biol 82:307-322

Warwick RM, Clarke KR, Gee JM (1990a) The effect of disturbance by soldier crabs Mictyris platycheles $\mathrm{H}$. Milne Edwards on meiobenthic community structure. J Exp Mar Biol Ecol 135:19-33

Warwick RM, Gee JM (1984) Community structure of estuarine meiobenthos. Mar Ecol Prog Ser 18:97-111

Warwick RM, Gee JM, Berge JA, Ambrose W Jr (1986) Effects of the feeding activity of the polychaete Streblosoma bairdi (Malmgren) on meiofaunal abundance and community structure. Sarsia 71:11-16

Warwick RM, Platt HM, Clarke KR, Agard J, Gobin J (1990b) Analysis of macrobenthic and meiobenthic community structure in relation to pollution and disturbance in Hamilton Harbour, Bermuda. J Exp Mar Biol Ecol 138:119-142

White DC, Findlay RH, Fazio SD, Bobbie RJ, Nickels JS, Davis WM, Smith GA, Martz RF (1980) Effects of bioturbation and predation by Mellita quinquiesperforata on sedimentary microbial community structure. In: Kennedy VA (ed) Estuarine perspectives. Academic Press, New York, p $163-171$

Widdicombe S, Austen MC (1998) Experimental evidence for the role of Bnssopsis lyrifera (Forbes, 1841) as a critical species in the maintenance of benthic diversity and the modification of sediment chemistry. J Exp Mar Biol Ecol 228:241-255

Wieser W (1953) Die Beziehung zwischen Mundhöhlengestalt, Ernährungsweise und Vorkommen bei freilebenden marinen Nematoden. Arkiv för Zoologi Ser 2, 4: $439-484$

Wikander PB (1980) Biometry and behaviour in Abra nitida (Müller) and A. Iongicallus (Scacchi) (Bivalvia, Tellinacea). Sarsia 65:255-268

Submitted: April 27, 1998; Accepted: August 10, 1998 Proofs received from author(s): October 27, 1998 